Article

\title{
High Responsivity in GaN Ultraviolet Photodetector Achieved by Growing on a Periodic Trapezoid Column-Shape Patterned Sapphire Substrate
}

\author{
Kuan-Ting Liu ${ }^{1, *}$, Shoou-Jinn Chang ${ }^{2}$ and Sean $\mathrm{Wu}^{3}$ \\ 1 Department of Electronic Engineering, Cheng Shiu University, Kaohsiung 83347, Taiwan \\ 2 Institute of Microelectronics, Department of Electrical Engineering Center for Micro/Nano Science \\ and Technology, Advanced Optoelectronic Technology Center, National Cheng Kung University, \\ Tainan 701, Taiwan; changsj@mail.ncku.edu.tw \\ 3 Department of Electronics Engineering and Computer Sciences, Tung Fang Design Institute, \\ Kaohsiung 82941, Taiwan; wusean.tw@gmail.com \\ * Correspondence: liu@gcloud.csu.edu.tw; Tel.: +886-7-735-8800; Fax: +886-7-733-1758
}

\begin{abstract}
GaN ultraviolet photodetector with metal-semiconductor-metal structure is achieved by growing on a periodic trapezoid column-shape patterned sapphire substrate using metalorganic chemical vapor deposition. Under 5-V reverse bias, the photodetector fabricated on such patterned sapphire substrate exhibits a lower dark current, a higher photocurrent, and a $476 \%$ enhancement in the maximum responsivity as compare with those of the photodetector fabricated on conventional flat sapphire substrate. It is also found that the much larger UV-to-visible rejection ratio and the fact that responsivity drops in a smaller cut-off region are observed from photodetector fabricated by using a periodic trapezoid column-shape patterned sapphire substrate. These phenomena may all be attributed to the reduction of threading dislocation density and the improved quality of GaN film, as well as the internal reflection and/or scattering effect on the interface between GaN film and the periodic trapezoid column-shape pattern of the substrate.
\end{abstract}

Keywords: GaN ultraviolet photodetector; periodic trapezoid column-shape patterned sapphire substrate; responsivity; UV-to-visible rejection ratio

\section{Introduction}

Nitride-based compounds are generally useful for optical devices such as light-emitting diodes (LEDs), laser diodes, and photodetectors (PDs) in green, blue, and ultraviolet (UV) wavelength regions [1-3]. The high-power UV GaN LEDs, for instance, have been intensively researched because they can be used as a pumping source for developing the white-light LEDs. The white-light LEDs are the most promising solid-state lighting method to replace the conventional incandescent and fluorescent lamps $[4,5]$. However, due to the large difference in the lattice constant, thermal expansion coefficient, $\mathrm{GaN}$ films grown on sapphire substrate are usually induced a large number $\left(\sim 10^{10} \mathrm{~cm}^{-2}\right)$ of threading dislocations (TDs) [6,7]. This can incur a significant degradation in the performance of GaN-based devices [8,9]. Therefore, how to further reduce the TD density is an important issue for fabricating high-performance UV LEDs or UV PDs. Many different growth methods have been applied to the nitrides in order to minimize TDs [10,11]. One technique commonly employed is epitaxial lateral overgrowth (ELOG), where either different masking procedure is used, or the growth conditions are modified for inducing later growth. These techniques require the interruption of growth that is a disadvantage for commercial applications $[12,13]$. This problem can be overcome by growing on a patterned sapphire substrate (PSS), where 
there is no interruption of the growth process [14,15]. Unlike that nitride LEDs with the conventional sapphire substrate, the nitride LEDs fabricated on lamp-form PSS improved the output power, external quantum efficiency, and reverse leakage current reported by Wuu et al. [16]. They attributed the improved results to the elimination of TDs and enhancement of the extraction efficiency using the PSS.

To explore fully the potential functions and development of III-nitrides, a similar concept is theoretically applicable to other GaN-based optoelectronics devices. UV PDs are important devices that can be used in various commercial and military applications, such as space communications, ozone layer monitoring, and flame detection. The various types of GaN-based UV PDs have been reported on sapphire substrates including p-n junction [17], p-i-n [18], Schottky diodes [19], metal-semiconductor-metal (MSM) [20], and heterojunction structures [21]. Among these structures, MSM PDs have attracted much attention because of their simplicity and high responsivity. MSM structures are also useful in optoelectronic-integrated-circuits (OEICs) due to ease of integrate, potential for high-speed, and compatibility with field effect transistor (FET) process technologies [22]. It has been reported that a high quality GaN Schottky barrier PD is grown on PSS by the use of parallel stripes along the sapphire $\langle 1 \overline{1} 00\rangle$ direction when compared to that prepared on the conventional flat sapphire substrate [23]. Besides, there has been some research to study the influences on the properties of dark current, UV-to-visible rejection ratio, and responsivity for GaN-based p-i-n UV PDs with different patterns of sapphire substrate [24,25]. In contrast, only few studies have so far been made at GaN-based MSM UV PDs fabricated by using PSS. Chang et al. have investigated that the GaN-based MSM UV PDs prepared on PSS can contribute to a much smaller dark leakage and the internal gain than those achieved from the PD fabricated on the conventional flat sapphire substrate [26]. However, the used structure on substrate pattern of GaN-based MSM UV PDs for their study is the shape of paralle stripe. It is well known that the improvement effects for the electrical and optical properties of GaN-based UV LEDs fabricated on PSS depend on different pattern shapes [27-29]. Consequently, the GaN-based MSM UV PDs may also induce a similarity of behavior as the GaN-based UV LEDs grown on different pattern shapes.

Recent advances in our knowledge, it is found that the GaN MSM UV PD grown on periodically geometrical PSS have not yet been reported. In this study, we investigate for the first time, the characteristics of GaN UV PD with MSM structure fabricated on periodic trapezoid column-shape patterned sapphire substrate (PTCPSS) using metalorganic chemical vapor deposition (MOCVD). We also report the fabrication and characterization of GaN MSM UV PD with PTCPSS. A more detailed study on structural, electrical, optical, and responsive properties of the fabricated PD prepared by such patterned substrate will be discussed.

\section{Experimental Procedure}

The PTCPSS used in this study is fabricated by standard photolithography and subsequent inductive couple plasma (ICP) etching in which $\mathrm{Cl}_{2} / \mathrm{BCl}_{3}$ gases are used. For fabricating PTCPSS, a photoresist layer is deposited by spin coater on top of the sapphire substrate as the mask. The photoresist layer is prepared to be a periodic column pattern, where the depth and diameter of column pattern are 2 and $2.8 \mu \mathrm{m}$, respectively. The column array with a spacing of $3.5 \mu \mathrm{m}$ is formed by using a standard photolithography process. Next, the sapphire substrate is etched using $\mathrm{Cl}_{2} / \mathrm{BCl}_{3}$ 
gases in an ICP etcher at $100 \mathrm{~V}$ dc bias. Finally, the photoresist mask is removed using a lift-off solution to complete the PTCPSS structures. The micrograph of the PTCPSS is examined by scanning electron microscopy (SEM), as shown in Fig. 1. Figure 1(a) shows the perspective view of PTCPSS. The microscopy can be observed that the PTCPSS containing a periodic trapezoid column-shape structure has a depth of $1.6 \mu \mathrm{m}$ with a sidewall angle of $70^{\circ}$. The top and bottom diameters of pattern are 2.8 and $4.6 \mu \mathrm{m}$, respectively, which are separated from each other in an interval of $1.4 \mu \mathrm{m}$. The top view of PTCPSS is shown in Fig. 1(b), we can also confirm that the trapezoid column-shape pattern is uniformly arranged and all the geometrical patterns are of equal size.

Afterward, GaN film is grown on the fabricated PTCPSS by MOCVD. Ttrimethylgallium (TMGa) and ammonia $\left(\mathrm{NH}_{3}\right)$ are used as the sources of gallium and nitrogen, respectively. The substrate is initially heated to $1100{ }^{\circ} \mathrm{C}$ in hydrogen $\left(\mathrm{H}_{2}\right)$ ambient to remove surface contamination, and then lowering to $550{ }^{\circ} \mathrm{C}$ to grow a 30 -nm-thick low-temperature $\mathrm{GaN}$ buffer layer. The temperature is subsequently raised to $1100{ }^{\circ} \mathrm{C}$ to grow a $2-\mu$ m-thick undoped GaN film.

Prior to the fabrication of MSM PD, the GaN film is dipped a diluted hydrochloric acid water solution $\left(\mathrm{HCl}: \mathrm{H}_{2} \mathrm{O}=1: 1\right)$ for $3 \mathrm{~min}$ to remove the native oxide. $\mathrm{Ni}(5 \mathrm{~nm}) / \mathrm{Au}(5 \mathrm{~nm})$ are subsequently deposited onto the GaN film by electron-beam evaporator as the Schottky contact electrodes for the fabrication of MSM PD. The MSM PD consists of two interdigitated contact electrodes, which is fabricated through standard photolithography and etching. The fingers of the contact electrodes are $10 \mu \mathrm{m}$-width and $150 \mu \mathrm{m}$-length with a spacing of $10 \mu \mathrm{m}$, and the detective area is $150 \times 510 \mu \mathrm{m}^{2}$. After contact electrodes deposition, Au layer is deposited to serve as bonding pads. For comparison, the GaN film and MSM PD fabricated on a conventional flat sapphire substrate (CFSS) under the same conditions are also prepared respectively. It should be noted that the fabricated PDs are not packaged and the performance of the PDs are all measured by probe. The TDs of GaN samples are examined by etch pit density (EPD) measurement. The as-grown GaN

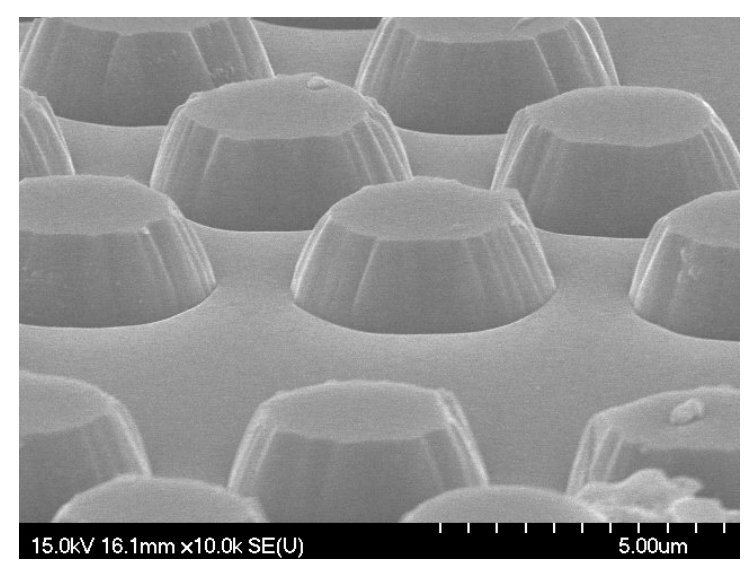

(a)

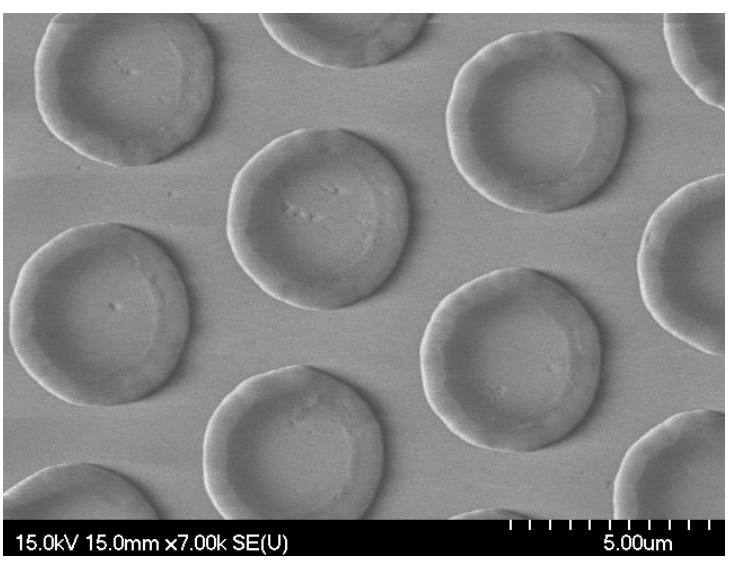

(b)

Figure 1. SEM micrographs of (a) perspective view and (b) top view on PTCPSS. 
samples are characterized by X-ray diffraction (XRD). Photoluminescence (PL) characteristics are determined using $325 \mathrm{~nm}$ He-Cd laser as excitation power, and the carrier concentration is evaluated by Hall effect measurement. A HP-4155B semiconductor parameter analyzer is used to measure the current-voltage $(I-V)$ characteristics of the fabricated PDs in dark and under illumination. For photocurrent measurements, a deuterium lamp illuminating from the front side of the fabricated PDs is used as the light source. A xenon arc lamp is used as the light source for spectral responsivity measurements, and a standard synchronous detection scheme is employed to measure the front-side illuminated detector signal. A calibrated UV-enhanced Si detector is used for signal detection.

\section{Results and Discussion}

For EPD measurements, the GaN samples are immersed in $\mathrm{H}_{3} \mathrm{PO}_{4}$ at $160{ }^{\circ} \mathrm{C}$ for 3 min. Figure 2 indicates the SEM cross-sectional micrographs of the etched GaN samples. In Fig. 2(a), it is found that vertical striations are clearly observed from the GaN film grown on CFSS. On the other hand, the vertical striations disappeared for the GaN film grown on PTCPSS, as shown in Fig. 2(b). This observation can be attributed to the enhanced lateral growth of the using PTCPSS.

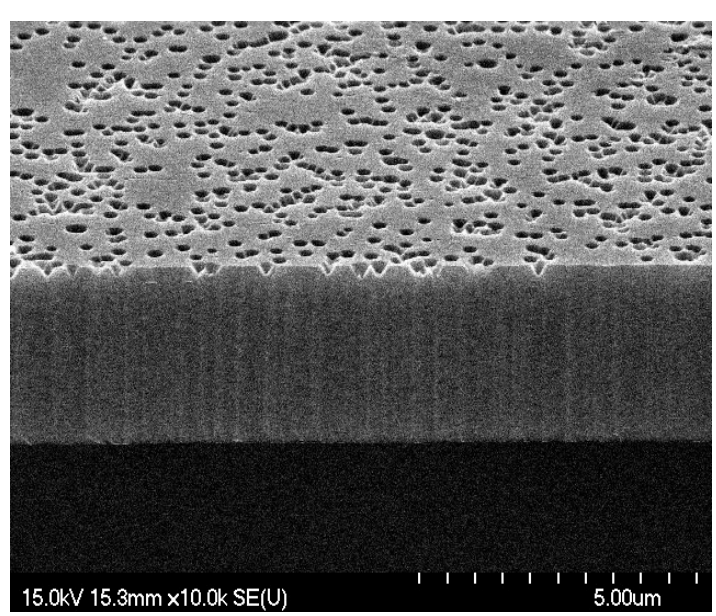

(a)

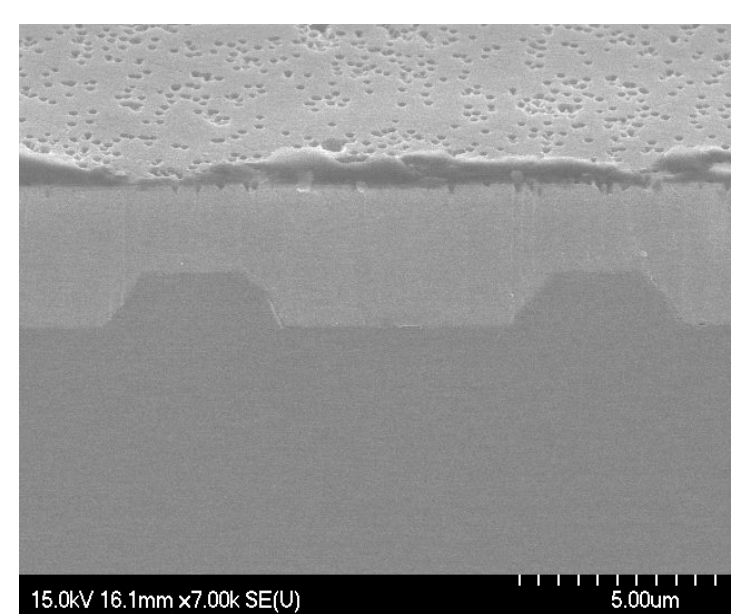

(b)

Figure 2. SEM cross-sectional micrographs of the etched GaN films grown on (a) CFSS and (b) PTCPSS.

Figure 3 shows the SEM surface morphologies of the etched GaN films grown on CFSS and PTCPSS, respectively. EPD of GaN film grown on CFSS is estimated to be $1 \times 10^{9} \mathrm{~cm}^{-2}$. Whereas, the EPD is only $3 \times 10^{8} \mathrm{~cm}^{-2}$ for GaN film grown on PTCPSS observed from Fig. 3(b). The much lower EPD observed from the GaN film implies that we can effectively reduce TD density by the use of PTCPSS. Figure 4 compares the XRD rocking curves of the GaN films grown on CFSS and PTCPSS. From XRD spectra, the full-width-half-maximum (FWHM) of the GaN (0002) peak is 414 and 316 sec for GaN films grown CFSS and PTCPSS, respectively. The sharp and narrow XRD rocking curve for GaN grown on PTCPSS reveals that the crystal quality of GaN film is drastically improved by using PTCPSS. Figure 5 shows the PL spectra measured at $20 \mathrm{~K}$ from the GaN films grown on CFSS and PTCPSS, respectively. It can be seen clearly that the PL spectrum of the GaN film grown on CFSS exhibits a relatively weak band-edge emission at $3.468 \mathrm{eV}$ and a notorious yellow band (YB) 


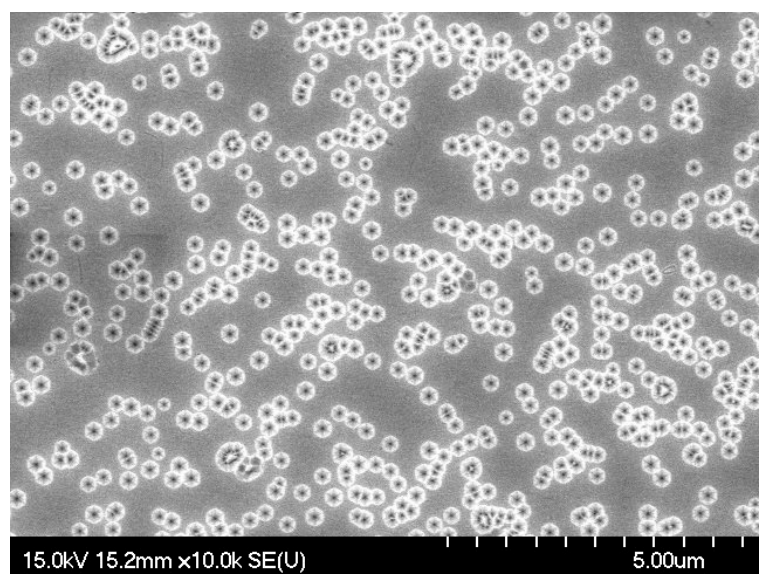

(a)

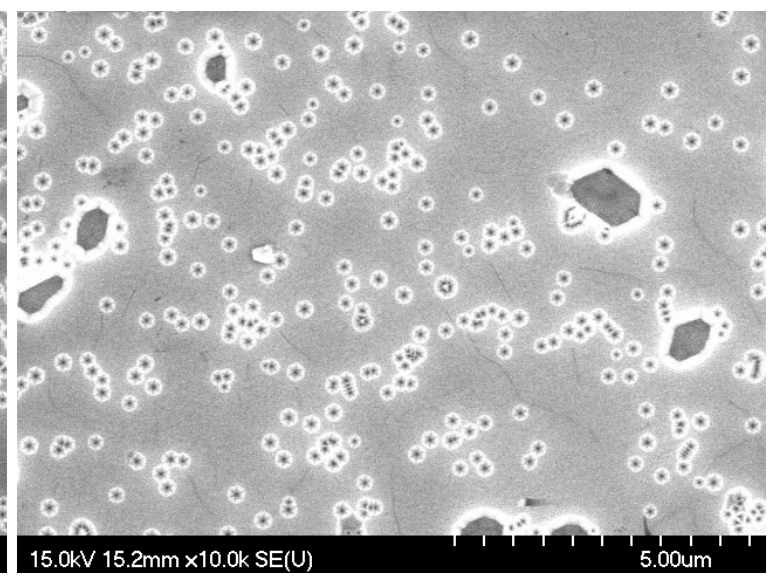

(b)

Figure 3. SEM surface morphologies of the etched GaN films grown on (a) CFSS and (b) PTCPSS.

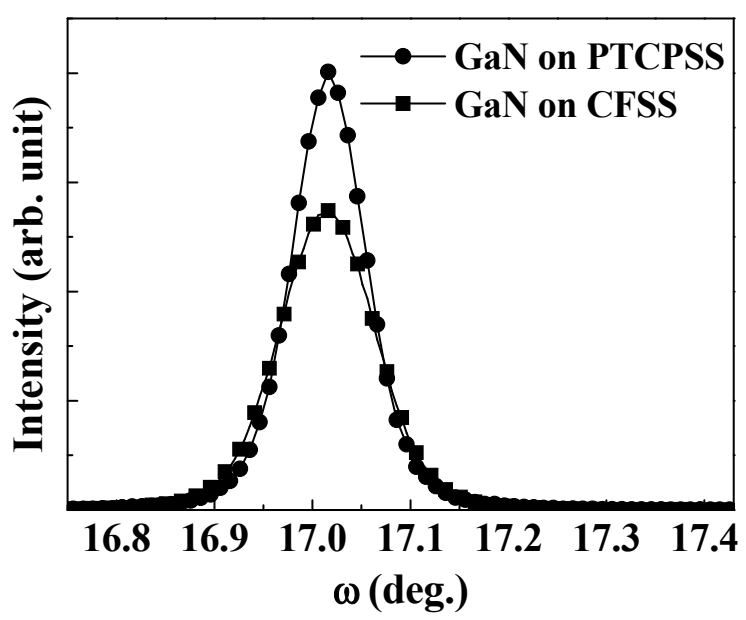

Figure 4. XRD rocking curves of the GaN films grown on CFSS and PTCPSS.

emission near $2.3 \mathrm{eV}$ [30]. In contrast, a strong band-edge emission PL peak with a sharp $14 \mathrm{meV}$ FWHM is observed from the GaN film grown on PTCPSS. The increase in the PL intensity and absence of YB emission indicate that crystal quality is improved and the TD density is reduced for GaN film grown on PTCPSS. From Hall effect measurement, the residual carrier concentration of GaN film is $1.37 \times 10^{17}$ and $3.22 \times 10^{16} \mathrm{~cm}^{-3}$ for CFSS and PTCPSS, respectively. The reduction in the residual carrier concentration demonstrates again that crystal quality is improved for GaN film grown on PTCPSS. The results of Hall effect measurement are in reasonable agreement with the observed results by XRD and PL measurements.

Figure 6 shows the $I-V$ characteristics of the two fabricated MSM PDs measured in dark and under illumination. With $5-\mathrm{V}$ reverse bias, the dark leakage currents of $5.3 \times 10^{-14} \mathrm{~A}$ and $1.2 \times$ $10^{-11} \mathrm{~A}$ are observed for the PDs fabricated on PTCPSS and CFSS, respectively, corresponding to a reduction of three orders of magnitude. It is also found that the measured dark leakage current is $5.3 \times 10^{-14} \mathrm{~A}$ for PD with PTCPSS and while that of ref. [26] is around $7 \times 10^{-12} \mathrm{~A}$. This 


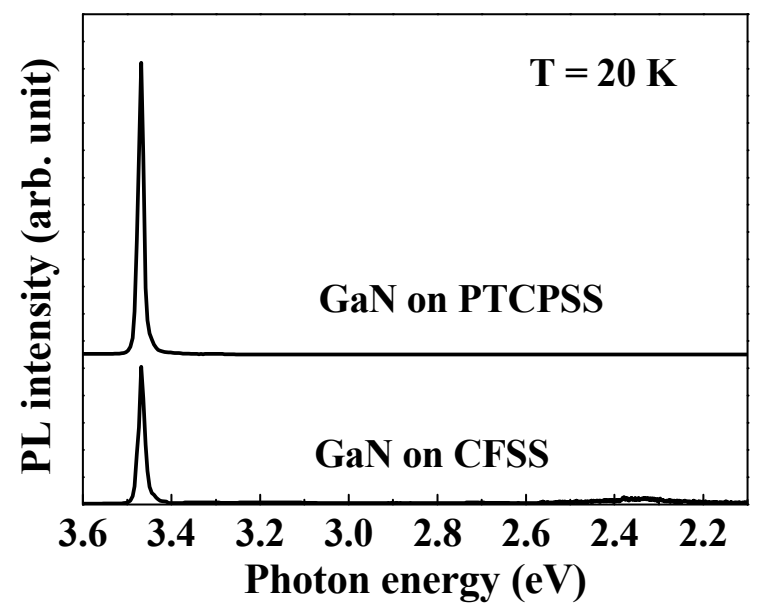

Figure 5. PL spectra measured at $20 \mathrm{~K}$ from the GaN films grown on CFSS and PTCPSS.

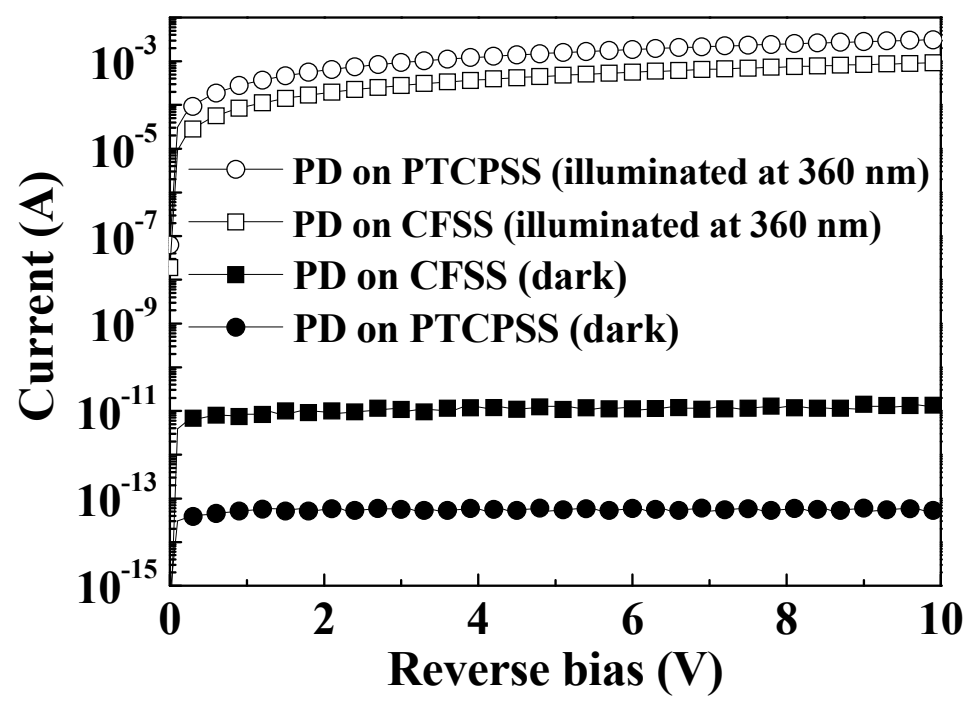

Figure 6. $I-V$ characteristics of the PDs fabricated on CFSS and PTCPSS measured in dark and under illumination.

phenomenon of the much smaller dark leakage current for our PD may be attributed to the effective suppression of TD density because of the difference of substrate pattern [31]. The reduced TD density of the PD with PTCPSS leads to a smaller probability for the occurrence of leakage current paths. On the other hand, it is found that the photocurrent from the PD with PTCPSS is larger than that from the PD with CFSS about one order of magnitude. Under 5-V reverse bias and 360-nm wavelength light illumination, the photocurrent of PD is $1.6 \times 10^{-3}$ and $4.6 \times 10^{-4} \mathrm{~A}$ for PTCPSS and CFSS, respectively. In order to clarify the influence of substrate on PD photocurrent, the transmittance spectra of the GaN films grown on CFSS and PTCPSS are performed by UV-Visible (UV-VIS) spectrophotometer, as shown in Fig. 7. The oscillations of transmittance spectra from both GaN samples are due to interference behavior. The observation of a steeper transition edge at about 


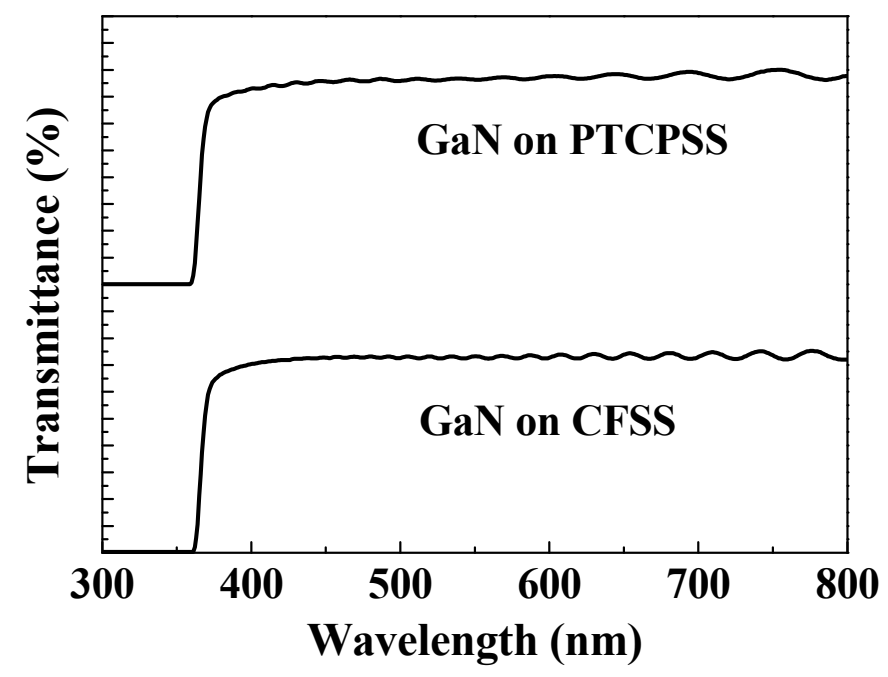

Figure 7. Transmittance spectra of the GaN films grown on CFSS and PTCPSS.

$360 \mathrm{~nm}$ (i.e., $3.4 \mathrm{eV}$ ) from the GaN film grown on PTCPSS reflects the bandgap of the GaN and indicates the crystal quality is good. When the incident photons are absorbed by GaN film that generates carriers and then contribute to the photocurrent. The partial unabsorbed photons reach substrate that are reflected and/or scattered back to GaN film via suitably geometrical substrate which probably generates again carriers and subsequently offer the photocurrent. Therefore, the fabricated periodic trapezoid column-shape pattern may improve the photon-recycling efficiency due to the interface between GaN film and PTCPSS resulting in reflecting and/or scattering effect. The larger photocurrent generated from the PD with PTCPSS may be resulting from the more photo-generated carriers by the improved quality of $\mathrm{GaN}$ film and the internal reflection and/or scattering effect on the periodic trapezoid column-shape pattern of the substrate. As a result, the photocurrent to dark current contrast is higher than ten orders of magnitude for the PD fabricated on PTCPSS with a $5 \mathrm{~V}$ bias voltage, whose value is larger than that of the PD fabricated on CFSS.

Figure 8 shows the spectral responses of both MSM PDs biased at $5 \mathrm{~V}$. It is found that the cutoff wavelength occur at $360 \mathrm{~nm}$ for both PDs. The maximum responsivities at $360 \mathrm{~nm}$ are 0.98 and 0.17 $\mathrm{A} / \mathrm{W}$ for the PDs fabricated on PTCPSS and CFSS, respectively. The measured maximum responsivity of $0.98 \mathrm{~A} / \mathrm{W}$ for the PD with PTCPSS is also found to be larger than that of around 0.38 $\mathrm{A} / \mathrm{W}$ reported by ref. [26]. In addition, we can also observe the responsivity drops in a sharp cut-off region of $100 \mathrm{~nm}$ for the PD with PTCPSS. In contrast, the cut-off region of responsivity for PD with CFSS is $200 \mathrm{~nm}$. The rejection ratio from UV to visible can be defined as the responsivity measured at $360 \mathrm{~nm}$ divided by the responsivity measured at $450 \mathrm{~nm}$. With such a definition, the UV-to-visible rejection ratios are evaluated to be $4.8 \times 10^{5}$ and $2.3 \times 10^{4}$ for PDs fabricated on PTCPSS and CFSS, respectively. The much higher of the maximum responsivity, a larger UV-to-visible rejection ratio and the fact that PD response drops in a smaller cut-off region are observed from PD with PTCPSS may all be attributed to the reduction of TD density and the improved quality of GaN film, as well as the internal reflection and/or back scattering effect on the periodic trapezoid column-shape pattern of the substrate. In other word, the experimental result shows the MSM UV PD based on GaN with high performance can be achieved by using PTCPSS with suitably geometrical substrate. 


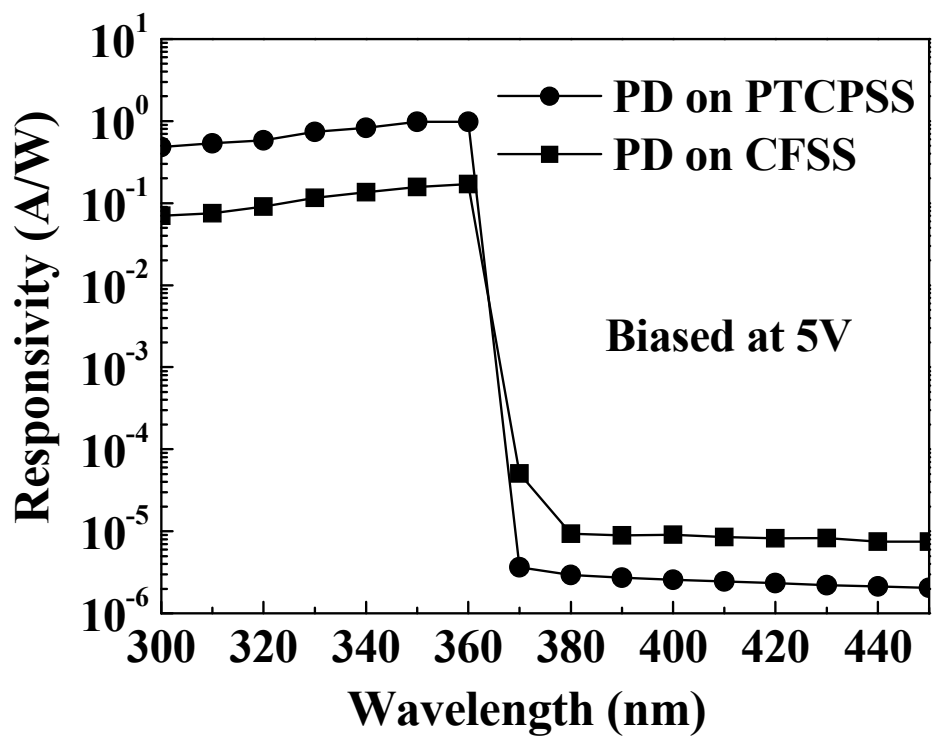

Figure 8. Spectral responses of the PDs fabricated on CFSS and PTCPSS at 5-V bias.

\section{Conclusions}

GaN UV PD with MSM structure fabricated on PTCPSS using MOCVD has been systematically investigated. Compared with the PD with CFSS, we can achieve a lower dark current of $5.3 \times 10^{-14}$ $\mathrm{A}$, a higher photocurrent of $1.6 \times 10^{-3} \mathrm{~A}$, and a $476 \%$ enhancement in the maximum responsivity from the PD with PTCPSS at $5-\mathrm{V}$ reverse bias. It is also found that the PD response drops in a smaller cut-off region of $100 \mathrm{~nm}$ for the PD with PTCPSS under 5-V applied bias. Furthermore, we also observe the UV-to-visible rejection ratio of the PD with PTCPSS is $4.8 \times 10^{5}$, while that of the PD with CFSS is only about $2.3 \times 10^{4}$ under 5 -V applied bias. These improved results observed from the PD fabricated on PTCPSS may all be attributed to the reduction of TD density and the improved quality of GaN film, as well as the internal reflection and/or scattering effect by the use of PTCPSS with suitably geometrical substrate.

In addition, the experimental result also shows that the properties in the dark leakage current and the maximum responsivity for our GaN MSM UV PD with suitably geometrical pattern of substrate are better than those of reported by ref.[26].

Author Contributions: Shoou-Jinn Chang provided the equipment for the experiments. Sean Wu assisted in discussion about the research.

Conflicts of Interest: The authors declare no conflict of interest. 


\section{References}

1. Nakamura, S.; Senoh, M.; Iwasa, N.; Nagahama, S. High-brightness InGaN blue, green and yellow light-emitting diodes with quantum well structures. Jpn. J. Appl. Phys. 1995, 34, L797-L799. [CrossRef] [PubMed]

2. Nakamura, S.; Senoh, M.; Nagahama, S.; Iwasa, N.; Yamada, T.; Matsushita, T.; Sugimoto,Y.; Kiyoku, H. High-Power, Long-Lifetime InGaN Multi-Quantum-Well-Structure Laser Diodes. Jpn. J. Appl. Phys. 1997, 36, L1059-L1061. [CrossRef] [PubMed]

3. Wang, C.K.; Chang, S.J.; Su, Y.K.; Chang, C.S.; Chiou, Y.Z.; Kuo, C.H.; Lin, T.K.; Ko, T.K.; Tang, J.J. GaN MSM photodetectors with TiW transparent electrodes. Mater. Sci. Eng. B 2004, 112, 25-29. [CrossRef] [PubMed]

4. Damilano, B.; Grandjean, N.; Pernot, C.; Massies, J. Monolithic white light emitting diodes based on InGaN/GaN multiple-quantum wells. Jpn. J. Appl. Phys. 2001, 40, L918-L920. [CrossRef] [PubMed]

5. Ozden, I.; Makarona, E.; Nurmikko, A.V.; Takeuchi, T.; Krames, M. A dual-wavelength indium gallium nitride quantum well light emitting diode. Appl. Phys. Lett. 2001, 79, 2532-2534. [CrossRef] [PubMed]

6. Tu, M.L.; Su, Y.K.; Chang, S.J.; Chuang, R. GaN UV photodetector by using transparency antimony-doped tin oxide electrode. J. Cryst. Growth 2007, 298, 744-747. [CrossRef] [PubMed]

7. Akasaki, I. Renaissance and progress in crystal growth of nitride semiconductors. J. Cryst. Growth 1999, 198/199, 885-893. [CrossRef] [PubMed]

8. Lester, S.D.; Ponce, F.A.; Craford, M.G.; Steigerwald, D.A. High dislocation densities in high efficiency GaN-based light-emitting diodes. Appl. Phys. Lett. 1995, 66, 1249-1251. [CrossRef] [PubMed]

9. Iwaya, M.; Takeuchi,T.; Yamaguchi,S.; Wetzel, C.; Amano, H.; Akasaki, I. Reduction of Etch Pit Density in Organometallic Vapor Phase Epitaxy-Grown GaN on Sapphire by Insertion of a Low-Temperature-Deposited Buffer Layer between High-Temperature-Grown GaN. Jpn. J. Appl. Phys. 1998, 37, L316-L318. [CrossRef] [PubMed]

10. Li, X.; Bishop, S.G.; Coleman, J.J. GaN epitaxial lateral overgrowth and optical characterization. Appl. Phys. Lett. 1998, 73, 1179-1181. [CrossRef] [PubMed]

11. Kidoguchi, I.; Ishibashi, A.; Sugahara, G.; Ban. Y. Air-bridged lateral epitaxial overgrowth of GaN thin films. Appl. Phys. Lett. 2000, 76, 3768-3770. [CrossRef] [PubMed]

12. Fini, P.; Zhao, L.; Moran, B.; Hansen, M.; Marchand, H.; Ibbetson, J.P.; Denbaars, S.P.; Mishra, U.K.; Speck, J.S. High-quality coalescence of laterally overgrown GaN stripes on GaN/sapphire seed layers. Appl. Phys. Lett. 1999, 75, 1706-1708. [CrossRef] [PubMed]

13. Takumi, S.; Hiroki, S.; Katsunori, Y.; Masahito, Y.; Kazumasa, H. Hydride vapor-phase epitaxy growth of high-quality GaN bulk single crystal by pitaxial lateral overgrowth. J. Cryst. Growth 1998, 189, 67-71. [CrossRef] [PubMed]

14. Wuu, D.S.; Wang, W.K.; Wen, K.S.; Huang, S.C.; Lin, S.H.; Huang, S.Y.; Lin, C.F. Defect reduction and efficiency improvement of near-ultraviolet emitters via laterally overgrown GaN on a GaN/patterned sapphire template. Appl. Phys. Lett. 2006, 89, 161105-161106. [CrossRef] [PubMed]

15. Cuong, T.V.; Cheong, H.S.; Kim, H.G.; Kim, H.Y.; Hong, C,H.; Suh, E.K.; Cho, H.K.; Kong, B.H. Enhanced light output from aligned micropit InGaN-based light emitting diodes using wet-etch sapphire patterning. Appl. Phys.Lett. 2007, 90, 131107-131108. [CrossRef] [PubMed]

16. Wuu, D.S.; Wang, W.K.; Shih, W.C.; Horng, R.H.; Lee, C.E.; Lin, W.Y.; Fang. J.S. Enhanced Output Power of Near-Ultraviolet InGaN-GaN LEDs Grown on Patterned Sapphire Substrates. IEEE Photon. Technol. Lett. 2005, 17, 288-290. [CrossRef] [PubMed]

17. Monroy, E.; Muñoz, E.; Sánchez, F.J.; Calle, F.; Calleja, E.; Beaumout, B.; Gibart, P.; Muñoz, J.A.; Cussó, F. High-performance GaN p-n junction photodetectors for solar ultraviolet applications. Semicond. Sci. Technol. 1998, 13, 1042-1046. [CrossRef] [PubMed]

18. Monroy, E.; Hamilton, M.; Walker, D.; Kung, P.; Sánchez, G.J.; Razeghi, M. High-quality visible-blind AlGaN p-i-n photodiodes. Appl. Phys.Lett. 1999, 74, 1171-1173. [CrossRef] [PubMed]

19. Chen, Q.; Yang, J.W.; Osinsky, A.; Gangopadhyay, S.; Lim, B.; Anwar, M.Z.; Asif Khan, M.; Kuksenkov, D.; Temkin, H. Schottky barrier detectors on GaN for visible-blind ultraviolet detection. Appl. Phys.Lett. 1997, 70, 2277-2279. [CrossRef] [PubMed]

20. Zhao, Z.M.; Jiang, R.L.; Chen, P.; Xi, D.J.; Luo, Z. Y.; Zhang, R.; Shen, B.; Chen, Z.Z.; Zheng, Y.D. Metalsemiconductor-metal GaN ultraviolet photodetectors on Si(111). Appl. Phys.Lett. 2000, 77, 444-446. [CrossRef] [PubMed] 
21. Huang, Z.C.; Chen, J.C.; Wickenden, D. Characterization of GaN using thermally stimulated current and photocurrent spectroscopies and its application to UV detectors. J. Cryst. Growth 1997, 170, 362-366. [CrossRef] [PubMed]

22. Parker, D.G.; Say, P.G. Indium tin oxide/GaAs photodiodes for millimetric-wave applications. Electron. Lett. 1986, 22, 1266-1267. [CrossRef] [PubMed]

23. Chang, S.J.; Wang, S.M.; Chen, T.P. Young, S.J.; Lin, Y.C.; Wu, S.L.; Huang, B.R. GaN Schottky Barrier Photodetectors Prepared on Patterned Sapphire Substrate. J. Electrochem. Soc. 2010, 157, J212-J215. [CrossRef] [PubMed]

24. Wang, G.; Lu, H.; Chen, D.; Ren, F.; Zhang, R.; Zheng, Y. High Quantum Efficiency GaN-Based p-i-n Ultraviolet Photodetectors Prepared on Patterned Sapphire Substrates. IEEE Photon. Technol. Lett. 2013, 25, 652-654. [CrossRef] [PubMed]

25. Huang, H.; Yan, D.; Wang, G.; Xie, F.; Yang, G.; Xiao, S.; Gu, X. GaN-based p-i-n ultraviolet photodetectors with a thin p-type GaN layer on patterned sapphire substrates. Chinese Optics Letters. 2014, 12. 092301. [CrossRef] [PubMed]

26. Chang, S.J.; Jhou, Y.D.; Lin, Y.C.; Wu, S.L.; Chen, C.H.; Wen, T.C.; Wu, L.W. GaN-Based MSM Photodetectors Prepared on Patterned Sapphire Substrates. IEEE Photon. Technol. Lett. 2008, 20, 1866-1868. [CrossRef] [PubMed]

27. Lee, J.H.; Oh, J.T.; Park, J.S.; Kim, J.W.; Kim, Y.C,; Lee, J.W; Cho, H.K. Improvement of luminous intensity of InGaN light emitting diodes grown on hemispherical patterned sapphire. Phys. Status Solidi C. 2006, 3, 2169-2173. [CrossRef] [PubMed]

28. Lee, T.X.; Gao, K.F.; Chien, W.T.; Sun, C.C. Light extraction analysis of GaN-based light-emitting diodes with surface texture and/or patterned substrate. Opt. Express. 2007, 15, 6670-6676. [CrossRef] [PubMed]

29. Chen, J.J.; Su, Y.K.; Lin, C.L.; Chen, S.M.; Li, W.L.; Kao, C.C. Enhanced output power of GaN-based LEDs with nano-patterned sapphire substrate. IEEE Photon. Technol. Lett. 2008, 20, 1193-1195. [CrossRef] [PubMed]

30. Dewsnip, D.J.; Andrianov, A.V.; Harrison, I.; Orton, J.W.; Lacklison, D.E.; Ren, G.B.; Hooper, S.E.; Cheng, T.S.; Foxon, C.T. Photoluminescence of MBE grown wurtzite Be-doped GaN. Semicond. Sci. Technol. 1998, 13, 500-504. [CrossRef] [PubMed]

31. Lee, S.W.; Oh, D.C.; Goto, H.; Ha, J.S.; Lee, H.J.; Hanada, T.; Cho, M.W.; Yao, T.; Hong, S.K.; Lee, H.Y.; Cho, S.R.; Choi, J.W.; Choi, J.H.; Jang, J.H.; Shin, J.E.; Lee, J.S. Origin of forward leakage current in GaN-based light-emitting devices. Appl. Phys. Lett. 2006, 89, 132117-132118. [CrossRef] [PubMed]

(C) 2016 by the authors; licensee Preprints, Basel, Switzerland. This article is an open access article distributed under the terms and conditions of the Creative Commons by Attribution (CC-BY) license (http://creativecommons.org/licenses/by/4.0/). 